\title{
The colonial overtones of overseas electives should make us rethink this practice
} Cite this as: BMJ 2021;375:n2770 http://dx.doi.org/10.1136/bmj.n2770 Published: 11 November 2021

\section{Will Smith final year medical student}

Since the outbreak of covid-19, overseas electives have been placed indefinitely on hold for UK medical students. With ever changing guidelines on social contact, health systems under intense pressure, and shifting rules on travel, universities are no longer able to sanction students travelling outside of the UK to complete their elective placements. This pause should provide us with an opportunity to consider whether the seemingly obvious advantages of overseas electives for future doctors can be justified, when in truth they hold both potential for harm and an underlying sentiment that is somewhat troubling.

Many UK medical students, as well as medical educators, will undoubtedly be disappointed by what is, to all intents and purposes, another sad casualty of this pandemic. But it's not just about students looking for that next high yield, "in real life" learning experience. In the General Medical Council's own Outcomes for Graduates, they state that as part of their education, future doctors should "describe and illustrate from their own professional experience the range of settings in which patients receive care, including in the community, in patients' homes, and in primary and secondary care provider settings." Although it is clear in the guidance that this relates to experiences gained in the home nations, it is often argued that experiencing other healthcare systems around the world provides medical students with the perfect barometer with which to compare and evaluate our own system in the UK.

The guidance for electives at the University of Liverpool, where I am a student, advises that the opportunity can help students to "broaden" their education, encourage study in a "different cultural, environmental, and social sphere," as well as "give students an opportunity to explore new disciplines, or old disciplines in greater depth." While these guidelines relate to both overseas and UK based electives, it is easy to read the supposed benefits and wonder whether any of these really can be adequately obtained by conducting an elective in the UK, where all of our university led medical training to date will have taken place.

I know that overseas electives, apart from being exciting, offer numerous benefits to medical students. For many students, it may be their first time travelling to another continent, an experience which can broaden their horizons and awareness of their socioeconomic privilege in the world. Many sources in the literature agree, with one highlighting how overseas electives can promote "reflective self-relativisation and contribute to medical professional identity formation." ${ }^{2}$

Despite this, something about the practice of overseas electives still feels broadly uncomfortable to me. The idea of scores of comparatively rich, British medical students embarking on international expeditions, often to "exotic" locations and those in the lower middle income category, evokes images for me of, at best, Charles Darwin and his HMS Beagle expedition (who was, incidentally, once a disgruntled medical student before he became a famous naturalist), and, at worst, James Cook and Francis Drake. If you don't see it yourself, you must admit that there can be something very "white saviour" about the endeavour. It is certainly not poles apart from the much criticised practice of "voluntourism"-a holiday that involves some form of (usually very unstructured and objectiveless) aid work.

As one commentary on surgical placements abroad highlighted, the practice of "new procedural techniques," "inadequate training," and "under-supervision” are all documented problems with international electives. ${ }^{3}$ It seems to me that they risk legitimising the idea that it is acceptable for students who haven't fully completed medical training in the UK to travel to other countries and try out their skills on those who are potentially less fortunate than those at home. The degree to which sufficient checks are in place to ensure competency before practice will of course vary depending on the country and setting, but the fact remains that UK medical students could be in a position to partake in practices on overseas electives that they wouldn't necessarily be allowed to at home.

Even electives that don't involve students in patient care are still beset by ethical questions. Many overseas elective programmes, for example, offer senior-led teaching as part of the experience (for which students are usually asked to foot the bill). But should the responsibility for teaching UK students fall on those working in underfunded healthcare systems? Not to mention the unregulated private companies who provide lucrative packages at astronomical rates: bundling together accommodation, hospital administrative costs, and the local on the ground knowledge and protection of native people-a process which the practice of unchecked overseas electives facilitates.

Although the benefits to medical students of travelling are evident, it seems clear that the practice of overseas electives needs to be reviewed. So as not to disadvantage students who have a particular interest in global health, perhaps the GMC or individual universities should consider offering application based and partially funded overseas elective programmes, which are regulated, fairly costed, and ensure ethical practice. Those where students are involved in care should have measured outcomes and sufficient support and guidance for 
students. For the rest, we should certainly encourage students to travel abroad and share their knowledge, but only once they are adequately proficient, with experiences gained under the full responsibility of the programme and nation in which they trained.

At a time when "decolonisation" of the medical curriculum is high on the collective agenda, with universities analysing their curriculums ${ }^{4}$ and students publishing their own textbooks as a rebuke to Western-centric medical education, ${ }^{5}$ can we really continue to let students take on responsibilities for patient care in other countries, which we wouldn't allow in our own? With the UK facing its own healthcare inequalities and gaps in care, perhaps students' time abroad would be better spent getting to understand the diversity within our own country.

Competing interests: none declared.

1 General Medical Council. Outcomes for Graduates 2018. https://www.gmc-uk.org/-/media/documents/outcomes-for-graduates-2020_pdf-

84622587.pdf?la=en\&hash=35E569DEB208E71D666BA91CE58E5337CD569945

2 Hayashi M, Son D, Nanishi K, Eto M. Long-term contribution of international electives for medical students to professional identity formation: a qualitative study. BMJ Open 2020;10:e039944. doi: 10.1136/bmjopen-2020-039944. pmid: 32801209

3 Ahmed F, Grade M, Malm C, Michelen S, Ahmed N. Surgical volunteerism or voluntourism - Are we doing more harm than good? Int J Surg 2017;42:69-71.

doi: 10.1016/j.jijsu.2017.04.020. pmid: 28433757

4 Mundasad S. The medical school trying to become anti-racist. BBC News. 17 August 2020. https://www.bbc.co.uk/news/health-53465113

5 Mukwende M, Tamony P, Turner M. Mind the Gap: A Handbook of Clinical Signs in Black and Brown Skin. St George's University of London. 2020. https://www.blackandbrownskin.co.uk/mindthegap 